\title{
THE EVOLUTION OF MATERNAL MORTALITY IN ROMANIA IN THE LAST DECADE, TRENDS AND CHALLENGES
}

\author{
Calin POPOVICI ${ }^{1,2}$, Petru ARMEAN ${ }^{2}$, Andrei KOZMA ${ }^{1 凶}$ \\ 1 "Alessandrescu-Rusescu" National Institute for Mother and Child Health, Bucharest, Romania \\ 2 "Carol Davila" University of Medicine and Pharmacy, Bucharest, Romania
}

Received 26 May 2021, Accepted 15 July 2021

https://doi.org/10.31688/ABMU.2021.56.3.08

\begin{abstract}
Introduction. In Romania, the number of cases of maternal death has decreased significantly in recent years.

Material and methods. The objective of this review is to assess maternal mortality in Romania in the last decade (2010-2019) in terms of the evolution of the number of cases and socio-demographic characteristics, by death groups and the identification of predictors of severe obstetric morbidity.

Results. The number of maternal deaths decreased during the analyzed period by almost $60 \%$ (from 51 deaths in 2010 to 20 in 2019). We observed the decrease of maternal death index from 24.0/100,000 live births in 2010 to 10.6/100,000 live births in 2019 . Considering maternal death groups, the result is mainly due to the decrease of abortion and indirect obstetrical risk, maintaining the trend of a higher mortality through direct obstetrical risk. Maternal deaths and mortality as a whole also decreased in terms of distribution by area for this period, generally maintaining the gap in favor of the rural environment. A number of factors have been identified as playing a predictive role for severe obstetric morbidity.
\end{abstract}

Conclusions. The decrease in maternal mortality has been influenced by several factors, including the increase in the number and quality of prenatal care,

\section{Résumé}

Lévolution de la mortalité maternelle en Roumanie au cours de la dernière décennie, les tendances et les défis

Introduction. Le nombre de cas de décès maternels a considérablement diminué en Roumanie ces dernières années.

Matériel et méthode. L'objectif de cette analyse rétrospective est d'évaluer la mortalité maternelle en Roumanie au cours de la dernière décennie (2010-2019) en termes d'évolution du nombre de cas et des caractéristiques sociodémographiques, par groupes de décès et, si possible, l'identification des prédicteurs de la morbidité obstétricale sévère.

Résultats. Le nombre de décès maternels a diminué au cours de la période analysée de près de $60 \%$ (de 51 décès en 2010 à 20 en 2019). On observe la diminution de l'indice de mortalité maternelle de 24,0/100 000 en 2010 à 10,6/100 000 en 2019 et du point de vue des groupes de décès, le résultat est principalement dû à la diminution de l'avortement et au risque obstétrical indirect, maintenant la tendance à une mortalité plus élevée par risque obstétrical direct. Les décès maternels et la mortalité dans son ensemble diminuent également en termes de répartition par zone pour la période analysée, maintenant généralement l'écart en 
reducing the risk of maternal death from indirect causes. Another factors are the quality and promptness of hospital care, more relevant in the case of deaths from direct obstetric causes; nevertheless, the risk of death in this group is still almost double. The analysis of severe obstetric morbidity can be performed considering the following groups of predictors: demographics (over 34 years old, etc.), general medical (hypertension, etc.) and obstetric factors (multiple pregnancies, antenatal hospitalizations, emergency cesarean section, etc). Their identification can determine a focus on women who require higher attention during pregnancy.

Keywords: maternal mortality, severe obstetrical morbidity, predictors. faveur du milieu rural. Un certain nombre de facteurs ont été identifiés qui jouent un rôle prédictif de la morbidité obstétricale sévère.

Conclusions. La diminution de la mortalité maternelle a été influencée par plusieurs facteurs, dont l'augmentation du nombre et de la qualité des soins prénatals, réduisant principalement le risque de décès maternel de causes indirectes. Un autre facteur en jeu est la qualité et la rapidité des soins hospitaliers, plus pertinents dans le cas des décès de causes obstétriques directes, mais le risque de décès dans ce groupe est encore presque le double. L'analyse de la morbidité obstétricale sévère peut être réalisée en considérant les groupes de prédicteurs suivants: données démographiques (plus de 34 ans, etc.), facteurs médicaux généraux (hypertension, etc) et obstétriques (grossesses multiples, hospitalisations prénatales, césarienne d'urgence, etc). Leur identification peut se concentrer sur les femmes qui ont besoin de plus d'attention pendant la grossesse.

Mots-clés: mortalité maternelle, morbidité obstétricale sévère, prédicteurs.

abortion are self-inflicted, performed in unsafe conditions, in countries like Romania, all these types of deaths are treated separately and not under maternal deaths from direct causes.

- Deaths due to indirect obstetrical risk are a consequence of a pre-existing pregnancy disease or a disease that coincided with the pregnancy, having no obstetric causes, but which could be aggravated by physiological changes in the pregnancy.

- Collateral deaths also called "accidental deaths" are those deaths that occur during pregnancy or postpartum but are not correlated with pregnancy

\section{Material AND Methods}

We performed a review of the published Romanian mortality studies used as data source, the maternal mortality reports of the Ministry of Health, National Institute of Public Statistics, National Centre for Statistics and Informatics in Public, Health Statistics and Information between 2010 and $2019^{3-10}$, the confidential maternal mortality studies conducted in the National Institute for Mother and Child Health (INSMC) Bucharest, Romania, and subsequent reports, articles, conference papers and presentations, including the Study of Infant Mortality and Maternal Mortality conducted in 2018-2019 by INSMC, international studies concerning maternal mortality and severe obstetric morbidity. 
Table 1. Structure of maternal deaths (abortion, direct and indirect obstetrical risk) between 2010 and 2019

\begin{tabular}{ccccccccccc}
\hline \multicolumn{1}{c}{ Maternal death 2010-2019 from abortion, direct and indirect obstetrical risk } \\
\hline Year & 2010 & 2011 & 2012 & 2013 & 2014 & 2015 & 2016 & 2017 & 2018 & 2019 \\
\hline Abortion & 11 & 6 & 6 & 6 & 6 & 5 & 0 & 2 & 1 & 1 \\
\hline Dir. Obst. risk & 22 & 23 & 11 & 14 & 11 & 13 & 10 & 9 & 10 & 12 \\
\hline Ind. Obst. risk & 18 & 21 & 9 & 7 & 7 & 9 & 7 & 13 & 7 & 7 \\
\hline Total death & 51 & 50 & 23 & 27 & 24 & 27 & 17 & 24 & 18 & 20 \\
\hline
\end{tabular}

Source: CNSISP-INSP, INS, HFA, Maternal mortality in Romania in 2010-2019 3-10

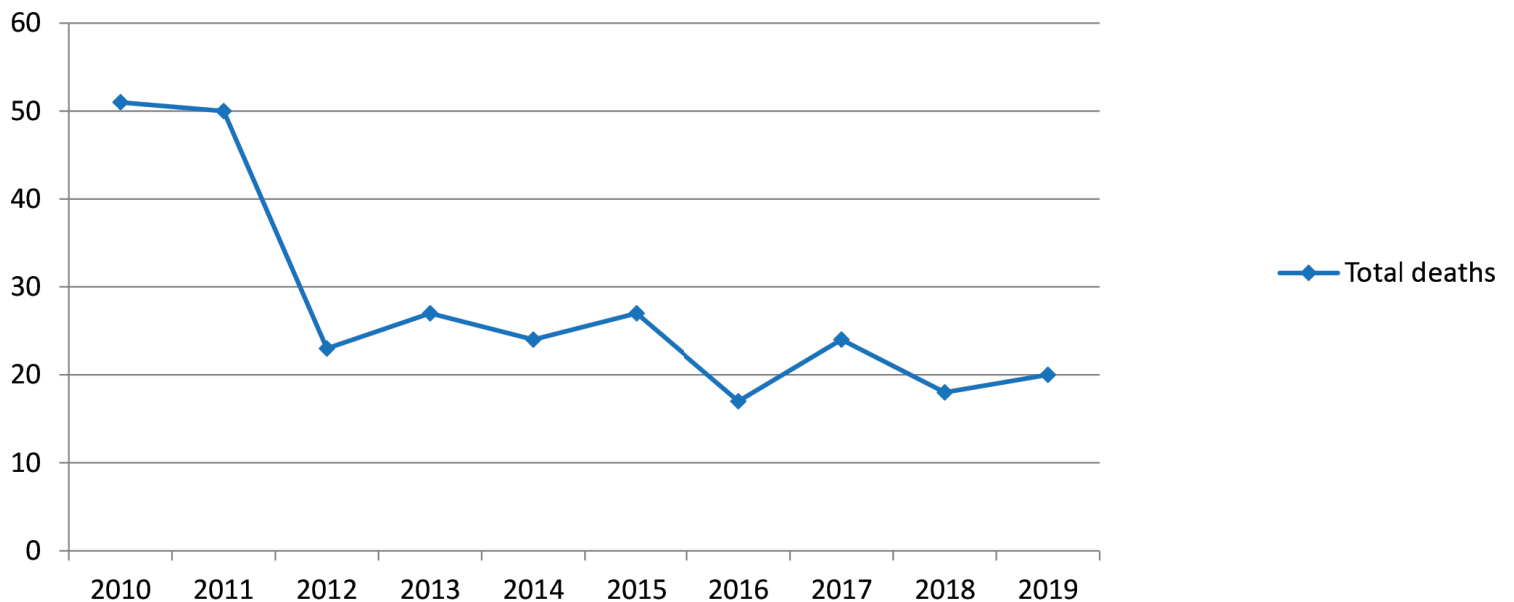

Fig. 1. Maternal deaths between 2010-2019.

The objective of this review is to assess the maternal mortality rate in Romania in the last decade (2010-2019), in terms of the evolution of the number of cases and socio-demographic characteristics, by death groups and the identification of predictors of severe obstetric morbidity.

We conducted the search by keywords, browsing medical databases as Google Scholar, Embase, PubMed, etc., and institutional sites (as: https://insp. gov.ro, https://cnsisp.insp.gov.ro, etc). The results include the studies of the National Center of Statistics and Informatics in Public Health of the National Institute for Public Health (CNSIBP-INSP) concerning maternal mortality during this period ${ }^{3-10}$. These and the studies of the National Institute for Mother and Child Health (INSMC) for this period were analyzed; outcome and findings were compared to results of international studies and discussed. Maternal mortality was analyzed according to the Romanian Minister of Health Order nr. 620/2001 ${ }^{11}$. Also, for the assessment of maternal mortality and severe maternal morbidity we used the tools recommended and developed by WHO, the Confidential Maternal
Death Analysis approach ${ }^{2}$. This approach implies an anonymous systematic multidisciplinary investigation of every maternal death, nationwide, with the purpose to identify causes of death and their avoidable or corrigible associated factors. Using this tool, the quality of hospital maternal care can we evaluated. WHO defines a maternal near-miss case as "a woman who nearly died but survived a complication that occurred during pregnancy, in childbirth or within 42 days of termination of pregnancy."12

\section{Results AND DISCUSSION}

The number of maternal deaths decreased during the last decade by almost 60\% (from 51 deaths in 2010 up to 20 in 2019 - Table 1, Fig.1). We can observe the decrease of the maternal death index from 24.0/100,000 live births in 2010 to 10.6/100,000 live births in 2019. Considering maternal death groups, the result is mainly due to the decrease of abortion and indirect obstetrical risk, maintaining the trend of a higher mortality through direct obstetrical risk (Table 2, Fig. 2). 
Table 2. Structure of maternal deaths from abortion, direct and indirect obstetrical risk between 2010 and 2019 - deaths and indexes per 100,000 live births ${ }^{3-10}$

\begin{tabular}{ccccccccccc}
\hline \multicolumn{7}{c}{ Maternal mortality } & $2010-2019$ & from abortion, direct and indirect obst. risk per 100.000 live births \\
\hline Year & 2010 & 2011 & 2012 & 2013 & 2014 & 2015 & 2016 & 2017 & 2018 & 2019 \\
\hline Abortion & 5,2 & 3,1 & 1,5 & 2,8 & 3,0 & 2,4 & 0,0 & 0,9 & 0,5 & 0,5 \\
\hline Dir. Obst. risk & 10,3 & 11,8 & 5,5 & 6,5 & 5,5 & 6,4 & 4,8 & 4,1 & 4,9 & 6,4 \\
\hline Ind. Obst. risk & 8,5 & 10,7 & 4,5 & 3,3 & 3,5 & 4,4 & 3,3 & 6,0 & 3,4 & 3,7 \\
\hline Total death & 24,0 & 25,5 & 11,4 & 12,6 & 11,9 & 13,1 & 8,1 & 11,2 & 8,7 & 10,6 \\
\hline
\end{tabular}

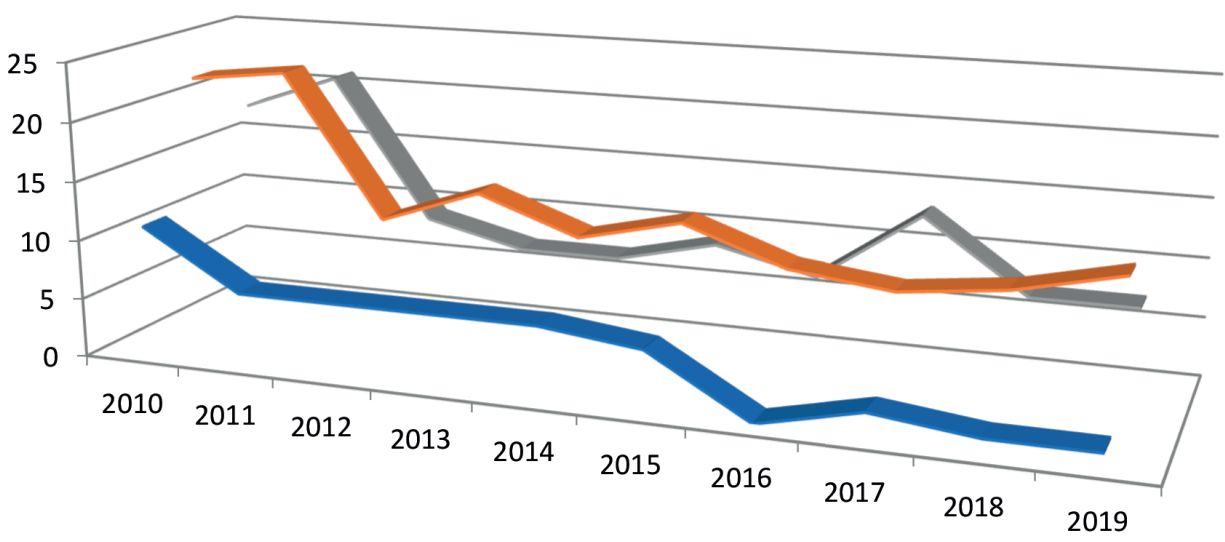

Abortion

Dir.Obst. risk

Indir.Obst. risk

Fig. 2. The structure of maternal deaths 2010-2019

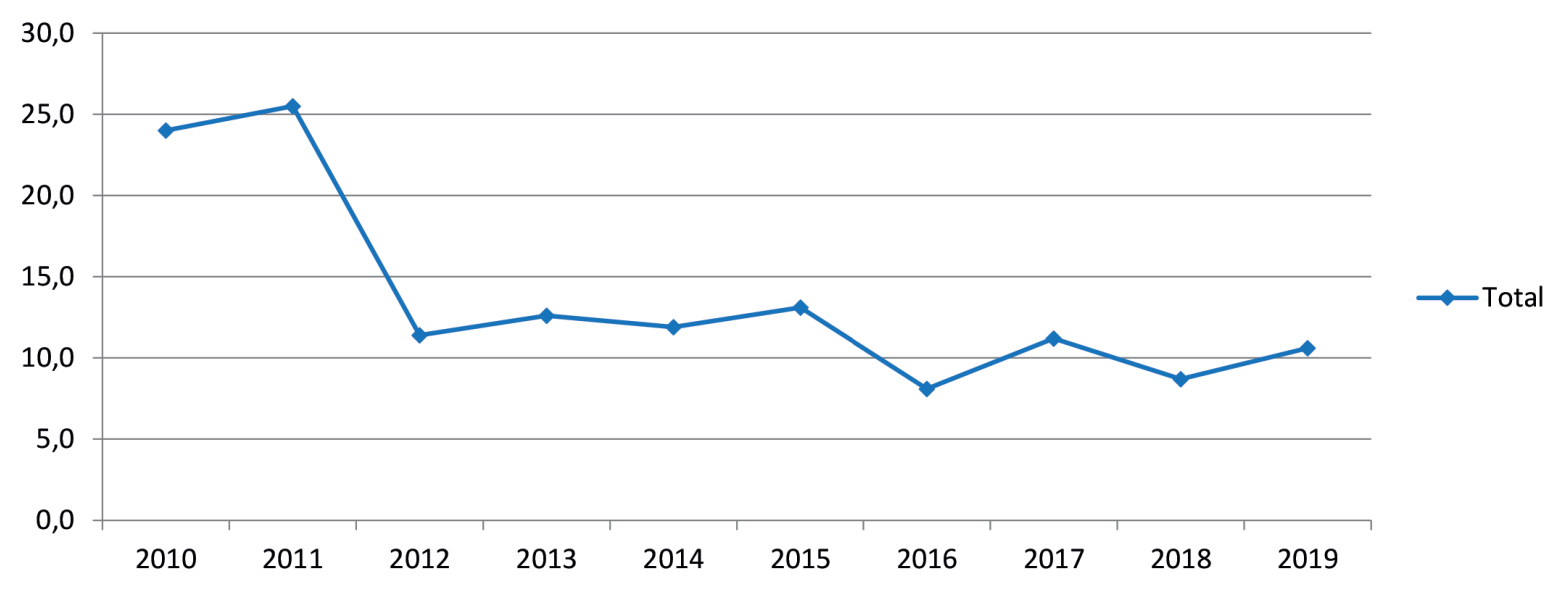

Fig. 3. Maternal mortality between 2010-2019 per 100.000 live births

During the whole period, the maternal death from direct obstetrical risk because of labour and birth complications (hemorrhagic, pre-eclampsia, HELLP syndrome - defined as hemolysis, elevated liver enzymes and low platelet count) and postpartum complications (sepsis) exceeded yearly cases of maternal death from indirect obstetrical risk, with one exception, in 2017. Examples of indirect deaths include epilepsy, diabetes, heart disease, infectious diseases and hormone-dependent tumours.

The concept of "obstetric transition", used for developing strategies to reduce maternal mortality, shows that all countries are gradually moving from a maternal mortality model with high values to a low one, from maternal deaths because of direct obstetric causes to indirect causes, from a natural history of pregnancy and childbirth to the institutionalization of maternity care and medicalization even over-medicalization of care and also to the significant increase in the age of women at first birth ${ }^{13}$.

The obstetrical transition is performed in 5 stages. According to this concept and low values criteria, such as maternal mortality rate $(<50$ deaths per 100,000 live births), as well as fertility rate, we 
Table 3. Maternal mortality according to urban/rural distribution between 2010-2019-10.

\begin{tabular}{ccccccccccc}
\hline \multicolumn{1}{c}{ Maternal mortality according to urban / rural distribution 2010-2019 } \\
\hline Year & 2010 & 2011 & 2012 & 2013 & 2014 & 2015 & 2016 & 2017 & 2018 & 2019 \\
\hline Urban & 22 & 23 & 10 & 11 & 14 & 12 & 7 & 10 & 8 & 6 \\
\hline Rural & 29 & 27 & 13 & 16 & 10 & 15 & 10 & 14 & 10 & 14 \\
\hline Total & 51 & 50 & 23 & 27 & 24 & 27 & 17 & 24 & 18 & 20 \\
\hline
\end{tabular}

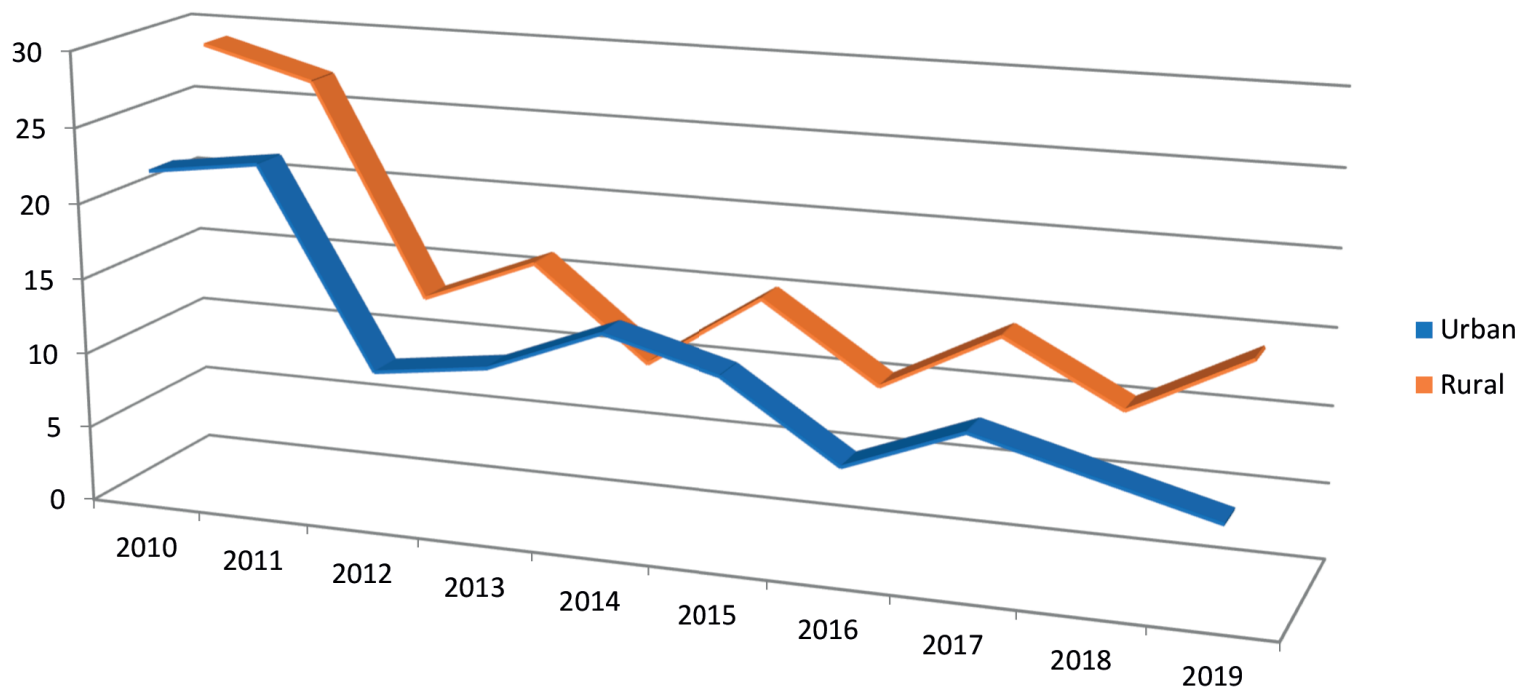

Fig. 4. Maternal mortality - urban/rural distribution 2010-2019.

consider that for the least 8 years Romania was in stage IV of the obstetric transition (Fig. 3). However, studying the reproductive behavior of the population, the increased percentage of pregnant women who do not access prenatal care (between 9 and 20\% depending on the data source $)^{14}$ and the registration of deaths at home, in Romania there are still subpopulations, usually vulnerable, with specific behavior to stages II-III, of the obstetric transition ${ }^{15}$. Nevertheless, although indirect causes of maternal death, mainly due to non-communicable/chronic diseases, should prevail we see that the direct causes of maternal death still exceed them. It is considered that in this stage, measures to reduce maternal mortality should focus on the quality and timeliness of appropriate interventions to eliminate delays in interventions leading to death.

Maternal deaths and mortality as a whole also decreased in terms of distribution by area for the period under review, generally maintaining the gap in favor of the rural environment (Table 3, Fig. 4). In this respect, we can consider that access to medical services for women living in rural areas is still lower and, according to medical files, an important percentage had an insufficient use of prenatal services or did not use any prenatal services, either from general practitioner or obstetrics specialist ${ }^{3-10,14}$
A number of factors have been identified as playing a predictive role for severe obstetric morbidity. Some of them are considered to be age over 34 years, non-white ethnic group, current or past hypertension (history), previous postpartum hemorrhage, birth by cesarean section or emergency cesarean section, multiple pregnancies, antenatal admission in hospital, social exclusion, etc ${ }^{16}$.

Some cases of maternal death due to indirect obstetrical risk could have been avoided. This concerns especially woman or pregnant woman, who should have accessed medical services and should have a medical record $^{17}$.

\section{Conclusions}

The decrease in maternal mortality in Romania has been influenced by several factors, including a better quality of prenatal care, mainly reducing the risk of maternal death from indirect causes. Another factors involved are the quality and promptness of hospital care, more relevant in the case of deaths from direct obstetric causes; nevertheless, the risk of death in this group is still almost double.

The analysis of severe obstetric morbidity can be performed considering the following groups of predictors: demographics (over 34 years old, etc), 
general medical (hypertension, etc) and obstetric factors (multiple pregnancies, antenatal hospitalizations, emergency cesarean section, etc). Their identification can allow to focus on women who require higher attention during pregnancy.

A qualitative analysis of maternal deaths, particularly of those from indirect obstetrical risk, revealed that some of the deaths could have been avoided. This concerns especially woman or pregnant woman who should have accessed medical services and should have a medical record, situation which would improve the quality of medical care. Nevertheless, the therapeutic guidelines and protocols for emergencies should be improved.

\section{Author Contributions:}

C.P. conceived the original draft preparation. C.P., A.P. and A.K. were responsible for conception and design of the review; C.P., A.P. and A.K. were responsible for the data acquisition. C.P., A.P. and A.K. were responsible for the collection and assembly of the articles/published data, and their inclusion and interpretation in this review. C.P., A.P. and A.K. contributed equally to the present work. All authors contributed to the critical revision of the manuscript for valuable intellectual content. All authors have read and agreed with the final version of the manuscript.

\section{Compliance with Ethics Requirements:}

"The authors declare no conflict of interest regarding this article"

"No funding for this study"

\section{Acknowledgements:}

None

\section{References}

1. World Health Organization. International statistical classification of diseases and related health problems, 10th rev. World Health Organization, 1994. Available at https:// apps.who.int/iris/handle/10665/38450 (accessed 10 May 2021)

2. World Health Organization. Beyond the numbers: reviewing maternal deaths and complications to make pregnancy safer. World Health Organization. 2004. https://apps.who. int/iris/handle/10665/42984 (accessed 10 May 2021)

3. Antal M, Ghenea G. Mortalitatea Materna in Romania 2012; Ministerul Sanatatii, Institutul National de Statistica Publica, Centrul National de Statistica si Informatica in Sanatate Publica Bucuresti; 2013. (Ministry of Health, National Institute of Public Statistics, National Centre for Statistics and Informatics in Public, Health Statistics and Information). Available at https://cnsisp.insp.gov.ro/index.php/date-statistice-pagina-de-descarcare/ (accessed 08 May 2021)

4. Botezat L, Ghenea G, Pirvu D, Botezat C, Cirtog C, Mateiuc D. Mortalitatea Materna in Romania 2013; Ministerul
Sanatatii, Institutul National de Statistica Publica, Centrul National de Statistica si Informatica in Sanatate Publica Bucuresti; 2014. (Ministry of Health, National Institute of Public Statistics, National Centre for Statistics and Informatics in Public, Health Statistics and Information); https://cnsisp.insp.gov.ro/index.php/date-statistice-pagina-de-descarcare/ (accessed 10 May 2021)

5. Botezat L, Ghenea G, Pirvu D, Botezat C, Cirtog C, Mateiuc D. Mortalitatea Materna in Romania 2014; Ministerul Sanatatii, Institutul National de Statistica Publica, Centrul National de Statistica si Informatica in Sanatate Publica Bucuresti; 2015. (Ministry of Health, National Institute of Public Statistics, National Centre for Statistics and Informatics in Public, Health Statistics and Information); https://cnsisp.insp.gov.ro/ (accessed 10 May 2021)

6. Botezat C, Cirtog C, Ghenea G, Pirvu D. Mortalitatea Materna in Romania 2015; Ministerul Sanatatii, Institutul National de Statistica Publica, Centrul National de Statistica si Informatica in Sanatate Publica Bucuresti; 2016. (Ministry of Health, National Institute of Public Statistics, National Centre for Statistics and Informatics in Public, Health Statistics and Information); https://cnsisp.insp.gov. ro/ (accessed 10 May 2021)

7. Botezat C, Cirtog C, Ghenea G, Pirvu D. Mortalitatea Materna in Romania 2016; Ministerul Sanatatii, Institutul National de Statistica Publica, Centrul National de Statistica si Informatica in Sanatate Publica Bucuresti; 2017. (Ministry of Health, National Institute of Public Statistics, National Centre for Statistics and Informatics in Public, Health Statistics and Information); https:// cnsisp.insp.gov.ro/wp-content/uploads/2018/03/ BI-Mortalitatea-Materna-an-2016.pdf (accessed 10 May 2021)

8. Cirtog C, Ghenea G, Botezat C, Pirvu D. Mortalitatea Materna in Romania 2017; Ministerul Sanatatii, Institutul National de Statistica Publica, Centrul National de Statistica si Informatica in Sanatate Publica Bucuresti; 2018. (Ministry of Health, National Institute of Public Statistics, National Centre for Statistics and Informatics in Public, Health Statistics and Information); https://cnsisp.insp.gov.ro/wp-content/uploads/2019/01/MORTALITATEA-MATERNA-2017. pdf (accessed 10 May 2021)

9. Cirtog C, Ghenea G, Botezat C, Pirvu D. Mortalitatea Materna in Romania 2018; Ministerul Sanatatii, Institutul National de Statistica Publica, Centrul National de Statistica si Informatica in Sanatate Publica Bucuresti; 2019. (Ministry of Health, National Institute of Public Statistics, National Centre for Statistics and Informatics in Public, Health Statistics and Information); https://cnsisp.insp.gov. ro/ (accessed 10 May 2021)

10. Cirtog C, Ghenea G, Pirvu D. Mortalitatea Materna in Romania 2019; Ministerul Sanatatii, Institutul National de Statistica Publica, Centrul National de Statistica si Informatica in Sanatate Publica Bucuresti; 2020. (Ministry of Health, National Institute of Public Statistics, National Centre for Statistics and Informatics in Public, Health Statistics and Information); https://cnsisp.insp.gov.ro/ (accessed 10 May 2021)

11. Order of the Minister of Health 620/11.09.2001 on the methodology for analyzing maternal mortality. Available at http://www.dspmm.ro/Ordin\%20620\%20din\%202001.pdf (accessed 14 May 2021)

12. Evaluating the quality of care for severe pregnancy complications: the WHO near-miss approach for maternal health. World Health Organization. ISBN 978-92-4-150222-1. World Health Organization 2011; Available at https:// 
www.who.int/reproductivehealth/publications/monitoring/9789241502221/en/ (accessed 07 May 2021)

13. Souza JP, Tuncalp O, Vogel JP, et al. Obstetric transition: the pathway towards ending preventable maternal deaths. BJOG. 2014;121 (Suppl. 1):1-4.

14. Study of Infant Mortality and Maternal Mortality. UNICEF and INSMC, 2018-2019. Available at https://www.insmc.ro/ studii-si-proiecte-de-cercetare/proiecte-cercetare-2012-2019/ (accessed 14 May 2021)

15. Stativa E, Stanescu A, Nanu I, Popovici C. Research on mater nal deaths in the hospitals in Romania, in 2016 - case study.
Anthropology and Demography. 2018, ISBN 978-973-27-2901-4; p. 267-275. Romanian Academy Publishing House.

16. Waterstone M, Bewley S, Wolfe C. Incidence and predictors of severe obstetric morbidity: casecontrol study. BMJ. 2001;322:1089-94.

17. Kozma A, Stativa E, Popovici C. Analysis of indirect maternal mortality in Romania in 2011 and 2014 - Associations between causes of death, anthropological and sociological factors. Proceedings of the Romanian Academy Series B. 2016;16(3):201-206. 